
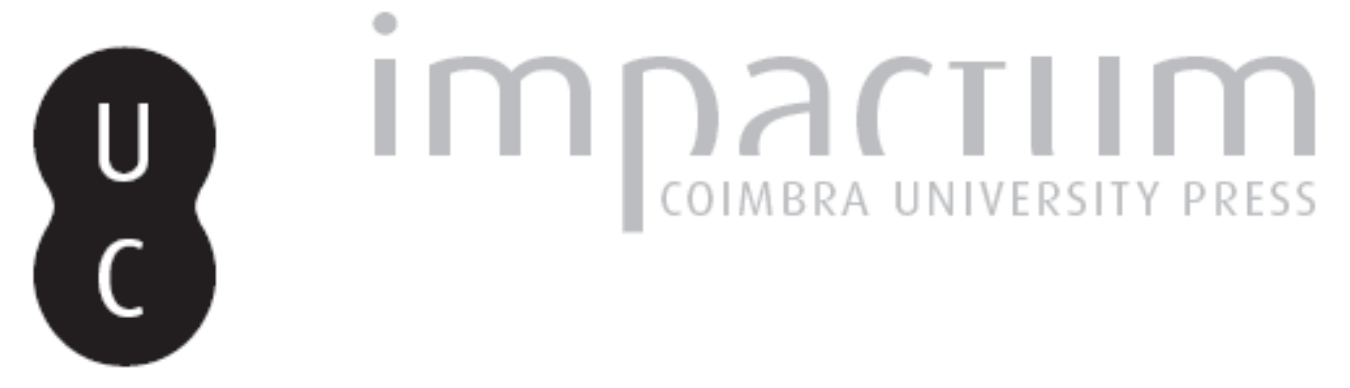

\title{
O tratado entre Ramsés II e Hattusili III
}

\section{Autor(es): $\quad$ Almeida, Júlia Pereira de}

Publicado por: Centro de História da Universidade de Lisboa

URL persistente:

URI:http://hdl.handle.net/10316.2/23717

DOI:

DOI:http://dx.doi.org/10.14195/0871-9527_20_5

Accessed : $\quad$ 26-Apr-2023 10:33:33

A navegação consulta e descarregamento dos títulos inseridos nas Bibliotecas Digitais UC Digitalis, UC Pombalina e UC Impactum, pressupõem a aceitação plena e sem reservas dos Termos e Condições de Uso destas Bibliotecas Digitais, disponíveis em https://digitalis.uc.pt/pt-pt/termos.

Conforme exposto nos referidos Termos e Condições de Uso, o descarregamento de títulos de acesso restrito requer uma licença válida de autorização devendo o utilizador aceder ao(s) documento(s) a partir de um endereço de IP da instituição detentora da supramencionada licença.

Ao utilizador é apenas permitido o descarregamento para uso pessoal, pelo que o emprego do(s) título(s) descarregado(s) para outro fim, designadamente comercial, carece de autorização do respetivo autor ou editor da obra.

Na medida em que todas as obras da UC Digitalis se encontram protegidas pelo Código do Direito de Autor e Direitos Conexos e demais legislação aplicável, toda a cópia, parcial ou total, deste documento, nos casos em que é legalmente admitida, deverá conter ou fazer-se acompanhar por este aviso.

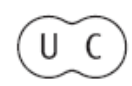




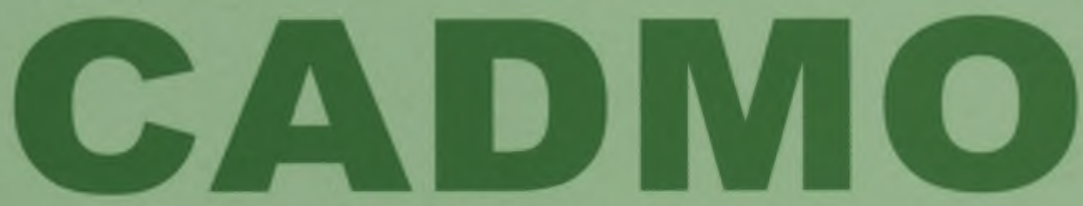

Revista de História Antiga

\author{
Centro de História \\ da Universidade de Lisboa
}

\title{
20
}

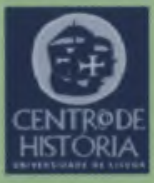

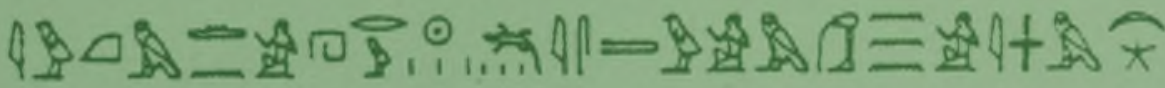

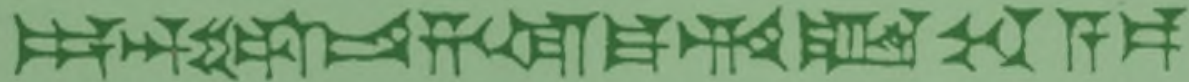

MHNIN AEI $\Delta$ E $\Theta E A ~ \Pi H \Lambda H I A \triangle E \Omega$ 


\title{
O TRATADO ENTRE RAMSÉS II E HATTUSILI III
}

\author{
JÚLIA PEREIRA DE ALMEIDA \\ Universidade de Lisboa \\ julia_almeida@hotmail.com
}

\section{Introdução}

A celebração de tratados era, no Próximo Oriente antigo, um instrumento frequente nas relações externas dos Estados ${ }^{(1)}$, celebrados entre soberanos e acabando por vincular os respectivos súbditos. O tratado celebrado entre Ramsés II (1279-1213 a. C.) e Hattusili III (1264-1239 a. C.) é o tratado mais antigo cujo texto nos chegou. Não só por este facto, mas também pela intervenção no processo de duas «mulheres fortes» à época, Nefertari (c. 1300-1250 a. C.), rainha principal de Ramsés II, e Puduhepa, esposa real de Hattusili III, despertou-nos desde logo o interesse.

O tratado surge relacionado com uma batalha violenta, ardilosa, repleta de jogadas esquemáticas, travada no primeiro quartel do século XIII a. C. (c. 1275 a. C.) junto de Kadech, no rio Orontes, na Síria do Norte. Quem ganhou afinal? Para alguns académicos o desfecho não é conclusivo: não terá havido vencedor, o mesmo é dizer, não houve perdedor. Para outros a vitória terá sido egípcia, como é o caso de Claire Lalouette ${ }^{(2)}$, para outros ainda a vitória foi hitita, como sugere José Nunes Carreira ${ }^{(3)}$, fazendo assim acreditar que a disputa continua ainda acesa, ontem como hoje. Se lermos atentamente as paredes de alguns templos ramséssidas, como o Ramesseum, Lucsor, Karnak, Abu Simbel e Abido, somos com efeito levados a pensar que o vencedor terá sido Ramsés II. Esta versão tem, no entanto, de ser vista com precaução, na medida em que, depois da batalha, foi o 
Império Hitita que continuou a dominar a Síria do Norte, incluindo a cidade de Kadech.

Raymond Westbrook salienta que normalmente se dividem os tratados do Próximo Oriente antigo em duas categorias: por um lado tratados paritários, ou inter pares, pelo qual dois soberanos independentes entram em acordo com base no princípio da reciprocidade, em regra com obrigações substancialmente idênticas, e, por outro lado, tratados vassalos, com carácter essencialmente unilateral, no qual o vassalo faz uma série de promessas sob juramento ao suserano ${ }^{(4)}$. No caso em análise trata-se claramente da primeira situação.

No presente artigo, procuraremos passar em revista, ainda que de forma necessariamente breve, a causa associada à origem do tratado, a batalha de Kadech. Causa bastante, mas não única, para a celebração deste tratado. Não seria o avanço assírio, ameaçando o Império Hitita, igualmente razão para este procurar aliados?

Procuraremos igualmente realçar alguns pontos do tratado que nos parecem de interesse, nomeadamente à luz do que eram as "relações internacionais" e a diplomacia dessa época, apresentando, em anexo, o seu texto.

O tratado surge então uns anos depois de uma batalha com uma causa claramente identificada: a progressão do rei hitita Muwatalli (1295-1271 a. C.) no Corredor sírio-palestiniano, ganhando uma série de cidades da zona, era claramente inadmissivel aos olhos de Ramsés II. A penetração hitita na Síria do Norte ameaçava assim a autoridade do faraó. Havia que intervir e, de novo, assegurar o domínio egípcio na região.

\section{A batalha de Kadech}

Muito haveria a dizer sobre a batalha de Kadech, decorrida no ano 5 de reinado de Ramsés II(5). Tal como Homero canta a Guerra de Tróia, o escriba Pentauer dedica um longo poema à batalha, "O Poema de Kadech ${ }^{(6)}$, registado nas paredes dos já referidos templos, bem como em alguns papiros: é o caso do Papiro Rafié, o Papiro Sallier III e o Papiro Chester Beatty III, verso. Como refere Nicolas Grimal, pelo menos treze versões, combinando três modos literários, o referido "Poema", mais desenvolvido e de pendor literário, o "Boletim»(7), em forma mais concisa, e várias representações, tornam esta batalha o evento militar egípcio mais bem documentado(8). 
Como protagonistas do confronto, Ramsés II e Muwatalli. Difícil será inovar sobre Ramsés II. Páginas e páginas foram escritas sobre este faraó guerreiro, exaltado pelas suas façanhas militares, na linha do seu antecessor, Seti I, e com a sua longa vida e características físicas singulares à época. Muwatalli, rei do Hatti, merece igual louvor, sendo que o tratamento que lhe é aplicado nos registos do confronto, o de "miserável chefe do Hatti», faz parte do tratamento corrente dado ao inimigo do Egipto.

Vive-se na verdade, como refere Claire Lalouette, um verdadeiro tempo de heróis ${ }^{(9)}$, pois mais a norte Aqueus e Troianos defrontam-se igualmente, num confronto de forças humanas e divinas.

No confronto de forças, uma verdadeira massa humana desloca-se de cada lado. O faraó reúne os seus súbditos e junta-lhes os mercenários chardanos, que vencera no ano 2 e que viriam a revelar-se de suma importância para o desfecho da batalha. Segundo o relato, é com os mercenários chardanos que Ramsés, desde o seu carro, sozinho, domina os inimigos, episódio amplamente retratado nas paredes dos referidos templos ${ }^{(10)}$. Muwatalli por seu turno, levara todos os seus vassalos e aliados da Ásia Menor e da Síria do Norte. E como refere Gurney, o exército que combateu o Egipto em Kadech foi o mais forte alguma vez reunido pelos reis hititas ${ }^{(11)}$.

As hostilidades prolongam-se por vários anos. No que respeita a Ramsés II, subsistem registos de combates seus tanto no país hitita como na fronteira egípcia ${ }^{(12)}$, existindo representações de tomada de fortalezas sírias e palestinenses, dominadas pelos hititas.

No ano 8 do reinado de Ramsés II, Muwatalli morre e querelas dinásticas enfraquecem o poderio do Hatti, opondo o filho de Muwatalli, Urhi-Tesub, e o irmão, Hattusili. Após uma curta governação de Urhi-Tesub como Mursili III (1271-1264 a. C.), acabará por subir ao poder o irmão, como Hattusili III.

As hostilidades terminariam pelo reconhecimento da igualdade, igualdade pelo menos avançada no tratado, entre os anteriores inimigos. Assim é que no ano 21 do reinado de Ramsés II, estando o faraó na sua cidade de Per-Ramsés, recebe dois mensageiros ${ }^{(13)}$ hititas, enviados, segundo a versão egípcia, para "suplicar a paz" a Ramsés. Os embaixadores traziam a proposta hitita de tratado, ainda que os termos empregues não possam ser verdadeiramente significativos de um inimigo "suplicando a paz", pelo que se tratará de um dos casos em que se deverá ler o texto com alguma precaução. 


\section{O tratado celebrado entre Ramsés II e Hattusili III}

É com a publicação dos arquivos reais hititas, descobertos em Boghazköi por Hugo Winckler, que se torna possível comparar as versões hieroglíficas e cuneiformes. Dos arquivos hititas foram recuperados fragmentos de duas tabuinhas de argila que reproduzem em acádico, a língua diplomática da altura, o tratado plasmado nos templos tebanos. Apesar de ter sido identificado por Winckler em 1906 como sendo a cópia do tratado celebrado com Ramsés II, apenas em 1916 o texto vem a ser publicado.

Ainda que haja diferenças da versão hieroglífica, Langdon e Gardiner avançam que pelo menos em vários parágrafos as tabuinhas são o texto original a partir do qual a versão egípcia foi feita ${ }^{(14)}$, parecendo ter sido o rei Hattusili III, o mais directamente ameaçado pelos avanços dos Assírios, a tomar a iniciativa de uma aproximação ao Egipto. Outros autores, como Claire Lalouette, são igualmente da opinião de que as bases do tratado terão sido estabelecidas pela parte hitita: terá sido redigido um projecto em acádico, numa tabuinha de prata, e enviada a Ramsés II, que devolve ao rei hitita um texto ligeiramente alterado ${ }^{(15)}$, facto que traduz uma diferença de monta em relação aos tratados actuais em que cada parte tem uma cópia idêntica. O exemplar hitita foi depositado em Heliópolis aos pés de uma estátua do deus solar, e esculpido, em hieróglifos, nas paredes de diversos templos: Karnak, Elefantina, na Núbia (Sudão), com relevo para Abu Simbel e Akcha. Por seu turno, o exemplar de Ramsés II foi depositado aos pés de uma estátua do deus hitita Techub e copiado para tabuinhas de argila depositadas nos arquivos oficiais da capital hitita, onde virão então a ser encontradas.

Refira-se que foi igualmente recuperada uma carta, escrita em acádico, em que Nefertari felicita a sua «irmã», Puduhepa, pelas boas relações fraternais que os seus maridos estabeleceram ${ }^{(16)}$. Importa aqui realçar o papel desempenhado pelas mulheres neste processo, pois não foram apenas os reis mas também as rainhas dos dois países a trocar correspondência. A intervenção de Nefertari no processo revela assim a importância que a mulher egípcia, da elite obviamente, podia ter, neste caso em assuntos de "Estado".

Da mesma forma, e como refere Gurney, a posição forte e independente é uma das características da rainha hitita ${ }^{(17)}$. Assim é que Puduhepa, filha de um sacerdote de Kizzuwatna, Pentipsarri, é frequentemente associada ao marido nos documentos de Estado, sendo 
demonstrativo não só a troca de correspondência com a rainha do Egipto e com o faraó, bem como o próprio facto de o seu selo oficial constar do tratado.

Como refere Luís Manuel de Araújo, poder-se-á dividir o tratado em cinco partes fundamentais ${ }^{(18)}$ :

1 - Introdução histórica que menciona os reis signatários e que recorda a luta anterior entre o Egipto e o Hatti;

2 - Garantias mútuas de não agressão e respeito;

3 - Aliança defensiva contra uma terceira potência;

4 - Extradição de refugiados políticos, reenviados a pedido do país de origem;

5 - Invocação da protecção divina para o cumprimento do tratado e para castigo de quem não o observar.

Ainda que, no texto que se conhece nas duas versões, haja uma correspondência assinalável, encontramos igualmente pontos divergentes. Assim, a versão cuneiforme coloca Ramsés como principal parte contratante, usando assim o faraó muitas vezes a primeira pessoa. $\mathrm{Na}$ versão hieroglífica é Hattusili quem emprega o pronome da primeira pessoa, e o seu nome e terra são mencionados antes de faraó e de Egipto, o que, de acordo com Langdon e Gardiner, está de acordo com a afirmação de que a representação de Karnak dá a transcrição da tabuinha de prata enviada a Ramsés por Hattusili(19).

É de notar que as versões em hieróglifos alternam com frequência o prenome e nome de Ramsés II ao longo do texto, recurso estilístico frequente na altura, enquanto que as tabuinhas utilizam apenas o nome ${ }^{(20)}$.

De outro modo, a versão egípcia tem uma introdução, o que não tem paralelo nos textos hititas, o que poderá significar que não foi transcrita da versão hitita mas composta por um escriba egípcio. No que respeita ao preâmbulo, por seu turno, este assume particular relevância por ser nele que se reconhece a responsabilidade de Muwatalli na ruptura do acordo existente entre Amen-hotep IV e Suppiluliuma, talvez renovado por Seti I e Muwatalli.

Para além disso, pela primeira vez um tratado compromete os sucessores dos contratantes, o que traduz uma alteração de relevo na medida em que até à altura as alianças celebradas entre soberanos deviam ser renovadas pelos seus sucessores ${ }^{(21)}$.

Uma referência especial merece a forma de tratamento usada entre o soberano do Egipto e o seu congénere do Império Hitita: «irmão». 
E é ainda de notar o tratamento por «irmã» reservado para Puduhepa e Nefertari, como foi referido na correspondência trocada entre as duas rianhas. Cohen e Westbrook chamam a atenção para o uso deste termo entre os "Grandes Reis" e para o uso do termo "fraternidade" entre eles. Numa linguagem bastante actual, denominam o período entre o final do século XVI a. C. e o século XII a. C. no Próximo Oriente, em termos políticos, como "Clube das Grandes Potências", na medida em que a área estava dividida entre as maiores potências que se viam como membros de um clube reservado. Neste contexto, usariam para si, então, os termos de "Grande Rei" e de "fraternidade" para descrever a sua relação(22).

Independentemente do tratamento mútuo por irmãos e da instituída forma de fraternidade, não existirá, no entanto, um reconhecimento de paridade total, por parte do Egipto, da sua contraparte. Reforçando esta ideia está o facto de as tabuinhas cuneiformes não fazerem qualquer distinção de título entre os reis do Egipto e do Hatti: são ambos "grande rei, rei do Egipto" e "grande rei, rei do Hatti». Já nas versões hieroglíficas temos por um lado "O grande soberano do Egipto" e por outro lado "o grande chefe do Hatti», com um título menos honorífico, em regra aplicado aos pequenos príncipes sírios e outros estrangeiros. A verdade é que o faraó era um deus em vida, enquanto que o rei hitita apenas seria um deus depois de morrer ${ }^{(23)}$.

No final, o tratado é colocado sob a garantia dos deuses dos dois países. No que respeita aos nomes das divindades, as versões hitita e egípcia traduzem-nos para o seu equivalente indígena. Assim, o deus egípcio do sol, Ré, será Chamach no texto hitita. O deus hitita do trovão, Techub, será Set no Egipto. Importa entretanto realçar que não está consignada no tratado a eventualidade de ruptura do apoio estabelecido. São, com efeito, os deuses dos dois países que agem como garantia do mesmo. Lembremos o tempo, lembremos as circunstâncias e a mentalidade e vivência à época. Falamos do século XIII a. C., em que a vivência religiosa e o respeito pelos deuses era a

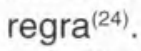

Com este tratado, o Próximo Oriente reencontra um período de paz e de prosperidade e ainda que as fronteiras não estejam definidas com precisão, pois este tratado não vem regulamentar um conflito territorial imediato a uma guerra mas reforçar o apoio e ajuda mútua, estão definidas de forma tácita, sendo o Orontes o limite reconhecido entre os dois "Estados" mais poderosos da altura. As trocas entre as duas potências revelam este clima de paz, comprovado, por exemplo, 
pelo facto de Ramsés enviar um arquitecto ao Hatti, Perimakhu, para construir o palácio de um príncipe vassalo de Hattusili, pedindo que este the envie ferro. Como refere Nicolas Grimal, o tratado reforça as relações pessoais entre as duas famílias reinantes, revisitadas nas 26 cartas dirigidas por Ramsés a Hattusili e nas 13 cartas dirigidas a Puduhepa ${ }^{(25)}$.

Mais tarde, a relação entre as duas potências é reforçada pelo casamento de Ramsés II com uma filha de Hattusili, a qual recebeu o nome egípcio de Maatneferuré(26) e um lugar privilegiado no palácio de Ramsés II. Não existe, no entanto, reciprocidade nesta matéria. Mário Liverani realça que a recusa egípcia da reciprocidade matrimonial é explicada pelo facto de o Egipto recusar reconhecer uma paridade completa de nível da sua contraparte ${ }^{(27)}$. No entanto, se é certo que até à altura não havia saída de princesas egípcias para outras cortes asiáticas, a ida de princesas asiáticas para a corte egípcia era comum, ocupando as mesmas por vezes um lugar não esperado, na medida em que esperariam maior visibilidade e no fundo poderiam ser simplesmente uma entre muitas.

Este casamento real envolve um largo processo de preparação e de negociações diplomáticas, culminando numa grandiosa cerimónia, representada em estelas comemorativas, sendo que entre as várias cartas trocadas se salienta uma endereçada por Ramsés II a Puduhepa ${ }^{(28)}$, que para além de confirmar o longo processo de negociações matrimoniais reforça o já referido papel político de relevo das mulheres, neste caso de Puduhepa, sendo a carta enviada à "sua irmã» Puduhepa muito semelhante à enviada ao «irmão" Hattusili. Ramsés II terá ainda desposado uma outra filha de Hattusili III, ainda que este evento não tenha tido a mesma relevância do primeiro casamento.

\section{Conclusão}

O tratado permitiu, como observámos, um período de estabilidade entre as duas potências. A batalha que está na sua origem, travada em Kadech, foi, segundo Cohen e Westbrook, um evento excepcional no contexto do sistema internacional existente na altura, já "estabelecido" desde o período de Amarna ${ }^{(29)}$, caracterizado por uma certa estabilidade e ambiente de paz na região por dois séculos. Para estes autores, as Cartas de Amarna constituem o primeiro sistema 
internacional que conhecemos ${ }^{(30)}$, na medida em que nesse período se observa pela primeira vez os "Grandes Poderes" de todo o Próximo Oriente a interagir, envolvidos em relações regulares de carácter dinástico, comercial e estratégico.

O tratado é interessante sob diversos aspectos. Um deles é, por exemplo, a cláusula de previsão de extradição de evadidos e o assegurar de um "bom" tratamento no seu país de origem, como podemos encontrar em tratados celebrados actualmente. $\mathrm{O}$ tratado permite-nos igualmente observar marcas de um código de conduta de alguma forma respeitado entre as partes: a forma de tratamento, a forma protocolar de se dirigir à contraparte, marcas de reciprocidade, ainda que esta reciprocidade não tenha sido sempre observada posteriormente, como vimos, nomeadamente em termos de política de casamentos. Do mesmo modo, a comparação das versões permite-nos observar que, ainda que se trate de uma relação em princípio inter pares, o posicionamento dos pares será diferente: bastará recordar que Hattusili não é o grande soberano do Hatti, é o "grande chefe do Hatti».

Frequentemente designado de tratado de paz entre Ramsés II e Hattusili III, tendo para tal como pano de fundo a batalha de Kadech, parece-nos, no entanto, mais interessante realçar este tratado enquanto acordo de apoio mútuo, nomeadamente perante inimigos, dado o contexto internacional da época e os interesses geo-estratégicos, nomeadamente hititas. $\mathrm{E}$ neste ponto julgamos pertinente salientar que, se da batalha de Kadech pode não ter saido vencedor claro (mas que após a mesma a zona fica sob a influência hitita), no que respeita ao tratado, parece-nos que a posição de supremacia estará do lado do Egipto, pois na altura a pressão estava sobre os Hititas, vinda da Assíria. E será que esta posição não poderá explicar o simples facto de Urhi-Tesub, refugiado no Egipto após as querelas dinásticas que se sucederam à morte de Muwatalli, não ser reenviado para o Hatti, sendo esse repatriamento obviamente importante para Hattusili e ser essa uma das cláusulas previstas no acordo?

Certo é que a celebração do tratado favorece, no Próximo Oriente, o retomar das trocas comerciais. E com o retomar do comércio internacional, essa forma silenciosa de diplomacia, não são apenas os produtos que se trocam, mas também as ideias, os cultos, as artes. 


\begin{abstract}
ANEXO
TRATADO CELEBRADO ENTRE RAMSÉS ॥ E HATTUSILI ॥|(31)
\end{abstract}

\title{
Versão egípcia
}

\section{Introdução}

Ano 21, primeiro mês da estação de Peret $^{(32)}$, dia 21 , sob a majestade do rei do Alto e do Baixo Egipto, Usermaetré-setepenré(33), filho de Ré, Ramessu-meriamon, dotado de vida para a eternidade e para todo o sempre, amado de Amon-Ré, de Horakthi, de Ptah "O que está a sul do seu muro", senhor da vida das Duas Terras, de Mut, senhora de Acheru, de Khonsu-Neferhotep, aparecendo em glória sobre o trono de Hórus dos vivos, como seu pai (Ré-?) Horakthi, para a eternidade e para todo o sempre.

Chegada dos mensageiros do Hatti

Neste dia, quando sua majestade se encontrava na cidade de Per-Ramsés Meriamon ${ }^{(34)}$, prestando os ritos de louvor a seu pai Amon-Ré, a Horakthi, a Atum, senhor das Duas Terras, o heliopolitano, a Amon de Ramessu-meriamon, a Ptah de Ramessu-meriamon, e a Set, o de Grande Força, filho de Nut, na mesma medida em que Ihe concedem uma infinidade de jubileus e uma eternidade de anos de paz, estando todas as terras egípcias e todas as terras estrangeiras prostradas sob as suas sandálias, para a eternidade.

Um mensageiro real ${ }^{(35)}$ chega, o comandante-delegado ...., o mensageiro real... (Usermaetré-)setepen(ré), .....-Teshub, e o mensageiro do Hatti..., trazendo (a tabuinha de prata, que) Ihe havia sido dada pelo grande chefe do Hatti, Hattusili, para que ela fosse entregue ao faraó - vida, prosperidade $e$ saúde -, para suplicar ${ }^{(36)}$ a pa(z junto da majestade de Usermaetré-)setepenré, filho de Ré, Ramessu-meriamon, dotado de vida para a eternidade e para todo o sempre, como seu pai Ré, cada dia.

Cópia $^{(37)}$ da tabuinha de prata que o grande chefe do Hatti, Hattusili, produziu para que fosse entregue ao faraó - vida, prosperidade e saúde pela mão do seu mensageiro Tarteshub e do seu mensageiro Ramose, para suplicar a paz junto da majestade (de Usermaetré-setepenré), filho de Ré, Ramessu-meriamon, touro dos reis, que estabelece as suas fronteiras, onde quer, em qualquer terra.

\section{O tratado - Preâmbulo ${ }^{(38)}$}

O tratado $^{(39)}$ que o grande príncipe do Hatti, Hattusili, o forte, filho de Mursili, o grande chefe do Hatti, o forte, o filho do filho de Suppiluliuma, o grande chefe do Hatti, o forte, fez numa tabuinha de prata para Usermaetré-setepenré, o grande chefe do Egipto, o forte, filho de Menmaetré(40), o grande 
soberano do Egipto, o forte, filho do filho de Menpehtiré(41), o grande soberano do Egipto, o forte - (é) um bom tratado de paz e de fraternidade, dando a paz... para a eternidade.

\section{Relacionamento anterior(42)}

No início e a partir do tempo eterno, no que respeita às relações entre o grande soberano do Egipto e o grande chefe do Hatti, o deus não permitiu hostilidade entre eles, através de um tratado(43). Mas, no tempo de Muwatalli, o grande chefe do Hatti, meu irmão, este combateu com (Ramessu-meriamon), o grande soberano do Egipto. Agora, a partir deste dia, vê Hattusili, o grande chefe do Hatti, está (n) um tratado para tornar permanente a situação que Ré e Set criaram para a terra do Egipto com a terra de Hatti, para não permitir hostilidades entre eles, para a eternidade.

\section{presente tratado ${ }^{(44)}$}

Vê, Hattusili, o grande chefe do Hatti, estabeleceu um tratado com Usermaetré-setepenré, o grande soberano do Egipto, a partir deste dia, de modo a permitir que exista boa paz e boa fraternidade entre nós, para sempre. E ele está em fraternidade comigo e em paz comigo, e eu estou em fraternidade com ele e em paz com ele, para sempre.

Desde que Muwatalli, o grande chefe do Hatti, meu irmão, se apressou em busca do seu destino(45), Hattusili senta-se, enquanto grande chefe do Hatti, no trono de seu pai; vê, eu estou com Ramessu-meriamon, o grande soberano do Egipto, nós estamos (juntos na) nossa paz e na nossa fraternidade; elas são melhores que a paz e a fraternidade de outrora, que existiam na terra.

Vê, eu, grande chefe do Hatti, estou com (Ramessu-meriamon), o grande soberano do Egipto, em boa paz e em boa fraternidade. E os filhos dos filhos (do) grande chefe do Hatti confraternizarão e estarão em paz com os filhos dos filhos de Ramessu-meriamon, o grande soberano do Egipto. Pois eles estão na nossa situação de fraternidade e (de paz. E a terra do Egipto), com a terra de Hatti, (estará) em paz e em fraternidade, como nós, para sempre. Não haverá hostilidades para as separar, até à eternidade.

\section{Cláusulas ${ }^{(46)}$}

Renúncia mútua de invasão(47)

O grande chefe do Hatti rão transporá (a fronteira do) país do Egipto - até à eternidade - para nele se apoderar da mais pequena coisa. De igual forma, Usermaetré-setepenré, o grande soberano do Egipto, não transporá (a fronteira da) terra (de Hatti para nele se apoderar da mais pequena coisa) - até à eternidade. 
Reafirmação dos anteriores tratados ${ }^{(48)}$

No que respeita ao tratado regular ${ }^{(49)}$ existente no tempo de Suppiluliuma, o grande chefe do Hatti, tal como o tratado regular existente no tempo de Muwatalli ${ }^{(50)}$, o grande chefe do Hatti, meu pai, respeitá-lo-ei. E vê, Ramessu-meriamon, o grande soberano do Egipto, respeita (a paz que ele) faz connosco, a partir deste dia; e nós respeitá-lo-emos e agiremos de acordo com o seu propósito.

\section{Aliança defensiva - para o Egipto ${ }^{(51)}$}

Se outro inimigo vier até às terras de Usermaetré-setepenré, o grande soberano do Egipto, e se este se dirigir ao grande chefe do Hatti, dizendo: "Vem comigo, como reforço contra ele"; o grande chefe do Hatti (deve ir ter com ele), o grande chefe do Hatti (deve) matar o seu inimigo. Mas se o grande chefe do Hatti não desejar vir (em pessoa), deverá enviar a sua infantaria e os seus carros de combate para matar o seu inimigo (de Ramsés).

Acção comum a tomar contra rebeldes ${ }^{(52)}$

Ou então se Ramessu-meriamon (o grande soberano do Egipto), estiver em cólera contra súbditos que Ihe pertençam e que tenham cometido contra ele qualquer outra ofensa, e for massacrá-los, o grande chefe do Hatti agirá com ele (para abater) todos (com quem) esteja enfurecido.

\section{Aliança defensiva ${ }^{(53)}$ - para o Hatti}

Mas se outro inimigo (vier) contra o grande chefe (do Hatti, Userm)aet(ré)-setepenré, (o grande soberano do Egipto deverá) ir na sua direcção em reforço para massacrar o seu inimigo (de Hattusili). (Mas) se Usermaetré-setepenré, o grande soberano do Egipto, não desejar vir (em pessoa), ele ...(deverá enviar a sua infantaria e os seus) carros de combate, ao mesmo tempo que dirigirá em retorno uma resposta à terra de Hatti.

Acção comum a tomar contra rebeldes - cláusula recíproca( ${ }^{(54)}$

Mas se súbditos do grande chefe do Hatti cometerem um delito contra ele, então Ramessu-meriamon...

Cláusula de sucessão(55)

... a (terra) de Hatti (e) a terra (do Egipto)....a vida. Se eu for(?) atrás do (meu) destino, então (?)Ramessu-meri(amon), o grande soberano do Egipto, vida eterna, deverá ir e vir (?) (para) a (terra de) Hatti... para causar... para fazer senhor (?), para fazer Usermaetré-setepen(ré), o grande soberano do Egipto, sua boca silenciosa para sempre. Agora depois que ele.... a terra de Hatti, e ele regressa... o grande chefe do Hatti, tal como...(56) 


\section{Extradição de fugitivos importantes do Egipto}

Se algum homem importante fugir da terra do Egipto e vier para (..), o grande chefe do Hatti, ou uma cidade pertencente às terras de Ramessumeriamon, o grande soberano do Egipto, e vierem ter com o grande chefe do Hatti, este não os receberá. O grande chefe do Hatti actuará de forma a que sejam reenviados a Usermaetré-setepenré, o grande soberano do Egipto, seu senhor, (por) isso.

\section{Extradição de fugitivos sem relevância do Egipto}

Ou então, se um homem ou dois homens, que não sejam conhecidos, fugirem (da terra do Egipto?) e forem para a terra de Hatti, deverão ser enviados de voita a Ramessu-meriamon, o grande soberano do Egipto.

\section{Extradição de fugitivos do Hatti(57)}

Ou então, se um homem importante fugir da terra de Hatti e for (para junto de User)maet(ré-)setepenré, o (grande) soberano do Egipto, ou uma cidade ou um distrito ou .... pertencente à terra de Hatti, que se refugie junto de Ramessu-meriamon, o grande soberano do Egipto, Usermaetré-setepenré, o grande soberano do Egipto, não os receberá. Ramessu-meriamon actuará de forma a que sejam enviados ao chefe (do Hatti?). Não poderão ficar.

\section{Extradição de fugitivos sem relevância do Hatti}

Da mesma forma, se um homem ou dois homens que (não) sejam conhecidos fujam para o país do Egipto, para se tornarem súbditos de outros, Usermaetré-setepenré, o grande soberano do Egipto, não Ihes permitirá que se instalem. Actuará de forma a que sejam reenviados ao grande chefe do Hatti.

\section{Testemunhas divinas do tratado}

Quanto a estas palavras do tratado (estabelecido?) pelo grande chefe do Hatti com Ramsés(-amado-de-)Amon, o grande soberano (do Egipto, são) escritas sobre esta tabuinha de prata, quanto a estas palavras, um milhar de divindades, dos deuses e deusas da terra de Hatti, e um milhar de divindades, dos deuses e deusas do país do Egipto, estão comigo como testemunhas destas palavras: Ré, senhor do céu, Ré da cidade de Arinna, Set, senhor do céu, Set do Hatti, Set da cidade de Arinna, Set da cidade de Zippalanda, Set da cidade de Betiarik, Set da cidade de Hissashapa, Set da cidade de Sarissa, Set da cidade de Alepo, Set da cidade de Lihzina, Set da cidade de .... Set .... Set de .... Set da cidade de Sahpin/Sakhypayna, Antaret do país do Hatti, o deus de Zitharias, o deus de Karzis, o deus de Hapantarias, a deusa da cidade de Karahana, a deusa ..., .... , a rainha do céu, os dois senhores do juramento, esta deusa, senhora da terra, a senhora do juramento, Ichara, a senhora (das) montanhas e dos rios da terra de 
Hatti, os deuses do país de Kizzuwatna, Amon, Ré, Set, os deuses, as deusas, das montanhas e dos rios da terra do Egipto, o céu, a terra, o grande mar, os ventos e as nuvens.

Pragas ou graças divinas para os que violem ou observem o tratado

E quanto a estas palavras que estão escritas sobre esta tabuinha de prata da terra de Hatti e da terra do Egipto, àquele que não as cumprir, que os mil deuses da terra de Hatti e os mil deuses da terra do Egipto destruam a sua casa, a sua terra e os seus súbditos. Mas aquele que cumprir as palavras que estão sobre esta tabuinha de prata, quer seja do Hatti ou que faça parte do povo do Egipto, e que não as negligenciar, um milhar de deuses da terra de Hatti em conjunto com um milhar de deuses da terra do Egipto actuarão para que seja próspero e para que viva com as suas casas, a sua (terra) e os seus súbditos.

\section{Extradição de egípcios do $\mathrm{Hatti}^{(58)}$}

Se um homem fugir da terra do Egipto, ou dois, ou três homens forem para junto do chefe do Hatti, o grande chefe do Hatti prendê-los-á e serão enviados de volta a Usermaetré-Setepenré, o grande soberano do Egipto. Mas quanto ao homem que será assim reconduzido a Ramessu-meriamon, o grande soberano do Egipto, que não se permita que o crime the seja imputado, que não se destrua a sua casa, as suas mulheres, ou os seus filhos, que não o matem, que não the façam mal aos seus olhos, aos seus ouvidos, à sua boca ou às suas pernas, que não se the impute qualquer crime.

\section{Extradição de hititas do Egipto}

Da mesma forma, se um homem fugir da terrra de Hatti, quer seja um, ou dois ou três, e se forem para junto de Usermaetré-setepenré, o grande soberano do Egipto, que Ramessu-meriamon, o (grande) soberano do Egipto, se apodere deles e que os reenvie ao grande chefe do Hatti e o grande chefe do Hatti não apresentará qualquer queixa contra eles, e não destruirão a sua casa, as suas mulheres ou os seus filhos, não será morto, não se the fará mal aos seus olhos, aos seus ouvidos, à sua boca ou às suas pernas; não se the imputará qualquer crime.

\section{Descrição da tabuinha}

O que está no centro da tabuinha de prata: na frente, encontra-se uma figura de Set abraçando uma imagem do grande chefe do Hatti, rodeado de palavras, dizendo: "O selo de Set, o soberano do céu, a garantia do tratado feito por Hattusili, o grande chefe do Hatti, o forte, filho de Mursili, o grande chefe do Hatti, o forte." No interior (da moldura) envolvendo as figuras está o selo (de Set, o soberano do céu). O que está no outro lado: uma imagem feminina da deusa da terra de Hatti abraçando uma imagem feminina da 
grande senhora do Hatti, rodeada por palavras, dizendo: «O selo de Ré da cidade de Arinna, senhor da terra, a garantia de Puduhepa ${ }^{(59)}$, senhora da terra de Hatti, filha da terra de Kizzuwatna, (sacerdotisa) da (cidade de) Arinna, senhora da terra, servidora da deusa." No interior (da moldura) envolvendo as figuras está o selo de Ré de Arinna, o senhor de toda a terra.

\section{Notas}

(1) Realça-se que no presente trabalho fomos colocados perante problemas conceptuais óbvios, por aplicação avant la lettre de conceitos como os de Estado, império, internacional ou política.

(2) LALOUETTE, L'Empire des Ramsès, p. 123.

(3) CARREIRA. Historiografia hitita, p. 19 e p. 27.

(4) WESTBROOK, "International Law in the Amarna Age", em Amarna Diplomacy, p. 39.

(5) Sobre a batalha de Kadech vide ARAÚJO, "A batalha de Kadech", em A Guerra na Antiguidade, pp. 55-102.

(6) Segundo Claire Lalouette, poder-se-á vislumbrar eventuais traços homéricos neste Poema. Sendo Homero colocado num período mais tardio, poder-se-á imaginar que Homero tenha conhecido este texto. Cf. LALOUETTE, L'Empire des Ramsès, p. 116. Miriam Lichtheim realça, por seu turno, que o verdadeiro tema do poema seria o papel heróico de Ramsés II neste confronto. Cf. LICHTHEIM, Ancient Egyptian Literature, II: The New Kingdom, p. 59. Refira-se que o elogio do rei, claro neste poema, era um topos tradicional da literatura egípcia e que o faraó, ainda que proclamado um deus no Egipto, estaria apesar de tudo sujeito às atribulações do cargo de soberano, muitas vezes vindas de quem the estava mais próximo, pelo que a literatura, tal como a arte, seria um meio de propaganda por eles utilizada. Hans Goedicke salienta, no entanto, que, atendendo a que a "publicação" da batalha de Kadech não começa assim que Ramsés II chega ao Egipto, aparentemente não se trataria de uma apologia para explicar o resultado inconclusivo de Kadech. Considerações sobre a "publicação"/divulgação da batalha de Kadech em GOEDICKE (ed.), Perspectives on the Battle of Kadesh, pp. 77-121.

(7) Vide Poema e Boletim em ARAÚJO, "A batalha de Kadech", em A Guerra na Antiguidade, pp. 84-100. Sobre o poema, vide igualmente WILSON, "The Texts of the Battle of Kadesh", em The American Journal of Semitic Languages and Literatures, pp. 266-287.

(8) GRIMAL, Histoire de l'Égypte ancienne, p. 332.

(9) Cf. LALOUETTE, L'Empire des Ramsès, p. 122.

(10) Mário Liverani realça esta noção de "um contra todos", patente na forma como Ramsés é retratado na batalha de Kadech. Realça igualmente que, atendendo à forma como a batalha é retratada nos referidos templos, destruindo Ramsés, sozinho, todo o exército hitita, e ao facto de este programa de celebração se ter prolongado o suficiente para se desenrolar ainda no período em que o tratado entre Ramsés II e Hattusili III é celebrado, tal poderá ter levado ao desagrado de Hattusili, salientado que a forma como o decorrer da batalha é apresentado seria contrária ao espírito de amizade e fraternidade plasmado no tratado. Cf. LIVERANI, Prestige and Interest, International Relations in the Near East ca. 1600-1100 b.C, pp. 119-120.

(11) GURNEY, The Hittites, p. 110.

(12) ERMAN e RANKE, La Civilisation Égyptienne, p. 716. 
(13) Neste tempo, são sobretudo os mensageiros reais e as escoltas civis e militares que levam a cabo as trocas diplomáticas e as alianças orientais, sendo que a correspondência internacional nos deixa ver as dificuldades que estes enfrentavam no desempenho da função de que estavam encarregues, dos perigos que teriam de enfrentar, da responsabilidade de negociar em nome do faraó, de o representar junto da futura esposa, para já não falar da certamente longa viagem que os aguardava. Cf. VALBELLE, Les Neuf Arcs. L'Égyptien et les étrangers de la Préhistoire à la conquête d'Alexandre, p. 179. Raymond Westbrook sublinha, por seu turno, a existência de evidências de inviolabilidade diplomática, na medida em que um ataque ou ofensa ao mensageiro pelo país anfitrião seria visto como um ataque ao seu país de origem e por isso mesmo casus belli. Cf. WESTBROOK, "International Law in the Amarna Age", em Amarna Diplomacy, p. 34.

(14) LANGDON e GARDINER, "The Treaty of Alliance between Hattusili, King of the Hitites, and the Pharaoh Ramesses II of Egypt", p. 180.

(15) LALOUETTE, L'Empire des Ramsès, p. 127. Como realçam Langdon e Gardiner, nesta fase incipiente das relações internacionais a noção de tratado não estava claramente definida. De qualquer maneira, aproxima-se já da forma de um contrato legal nas palavras empregues, na divisão em parágrafos e na alternância de condições semelhantes dadas e pretendidas. No uso da primeira pessoa, no facto de cada parte contratante ter a sua versão, e nas alusões pessoais ocasionais continua, por seu turno, aproximado da forma utilizada na correspondência diplomática da altura. Cf. LANGDON e GARDINER, "The Treaty of Alliance between Hattusili, King of the Hittites, and the Pharaoh Ramesses II of Egypt", p. 199.

(16) ERMAN e RANKE, La Civilisation Égyptienne, p. 722. Vide carta de Nefertari a Puduhepa em LANGDON e GARDINER, "The Treaty of Alliance between Hattusili, King of the Hittites, and the Pharaoh Ramesses II of Egypt", pp. 203-204.

(17) GURNEY, The Hittites, pp. 68-69.

(18) ARAÚJO, «A batalha de Kadech», em A Guerra na Antiguidade, p. 78.

(19) LANGDON e GARDINER, "The Treaty of Alliance between Hattusili, King of the Hitites, and the Pharaoh Ramesses II of Egypt", p. 185.

(20) Desde o Império Antigo a titulatura real integrava o nome de Hórus, o nome de Nebti (o das Duas Senhoras), o nome de Hórus de Ouro, o prenome e por último o nome.

(21) Conf. LALOUETTE, L'Empire des Ramsès, p. 128.

(22) COHEN e WESTBROOK, Amarna Diplomacy, The Beginnings of International Relations, p. 6. De acordo com estes autores, o Egipto teria entrado para este "Clube" no século XV a. C. após as campanhas de Tutmés III. Os outros membros seriam o Mitanni, a Babilónia, o Hatti e a Assíria.

(23) É, no entanto, interessante que nas Cartas de Amarna, que abrangem os reinados de Amen-hotep III e de Akhenaton, ambos da XVIII dinastia, e possivelmente um outro rei, Semenkhkaré ou Tutankhamon, o faraó permitisse ser chamado de rei, com o mesmo termo usado para o rei do Hatti, da Babilónia, da Assíria e do Mitanni, sabendo que na ideologia egípcia o faraó não tinha par. Rodolfo Ragionieri avança que, enquanto no Egipto o faraó era um deus, pelo menos do ponto de vista da sua imagem pública, fora do Egipto, no relacionamento com outros "Grandes Reis", seria supostamente de igual ranking, havendo, assim, um cruzamento de diferentes factores: poder, identidade interna do rei e o ajustamento da ideologia de fraternidade, um elemento básico das relações entre Estados, às diferentes exigências dos governantes. Cf. RAGIONIERI, "The Amarna Age", em Amarna Diplomacy, p. 49. De qualquer forma, o léxico internacional, nomeadamente o 
termo «rei», mesmo que o faraó permitisse que fosse usado em comunicações internacionais, não seria reproduzido nas inscrições egípcias, onde um rei estrangeiro seria chamado no máximo de príncipe ou chefe, como no caso aqui presente.

(24) Desta religiosidade egípcia encontramos igualmente marcas nos textos relativos à batatha e no próprio conflito, destacando-se a atribuição de nomes de deuses às quatro divisỏes que compunham as forças egipcias: Amon, Ré, ou Pare, como era denominado no Império Novo, Ptah e Set (ou Sutekh, no Império Novo). Ramsés lidera, claro, a divisão de Amon. Afinal estamos no Império Novo, em que Amon domina o panteão dos deuses, qual Zeus ou Júpiter mais tarde.

(25) GRIMAL, Histoire de l'Égypte ancienne, p. 337.

(26) "A que vê a beleza de Ré", ou "A verdade é a beleza de Ré".

(27) LIVERANI, "The Great Power's Club», em Amarna Diplomacy, p. 26.

(28) Vide a carta de Ramsés II a Puduhepa em LALOUETTE, L'Empire des Ramsès, pp. 132-133 .

(29) COHEN e WESTBROOK (Ed.), Amarna Diplomacy, The Beginnings of International Relations, p. 11. Os autores colocam o colapso deste sistema coincidindo com o desaparecimento do Hatti.

(30) Muito embora não marque o princípio das «Relações Internacionais" na história, na medida em que os primeiros relatos escritos decifráveis do princípio do terceiro milénio a. C. já revelam um mundo de "cidades-estado", que trocavam mensageiros, negociavam alianças e celebravam tratados. COHEN e WESTBROOK (Ed.), Amarna Diplomacy, The Beginnings of International Relations, p. 10. Chamamos aqui a atenção para o ponto de vista de Geoffrey Berridge, que contrariando a visão de Raymond Cohen de uma diplomacia "Sofisticada e efectiva" de Amarna, avança que se trata de uma diplomacia adequada ao período e aos interesses dos "Grandes Poderes", sendo até algo rudimentar, o que se pode esperar dado o facto de ser necessariamente lenta, de se expressar numa língua que não é a língua materna dos correspondentes, com todas as más interpretações que tal pode gerar. No entanto, o próprio facto de ela existir, demonstra um equilíbrio de poder entre Estados com um mínimo de interdependência, especialmente os envolvidos no comércio, gerando pressão para uma dipiomacia modestamente efectiva. Ver BERRIDGE, "Amarna Diplomacy", em Amarna Diplomacy, p. 244.

(31) Para a tradução que aqui se propõe da versão egípcia, foram confrontadas as versões de Claire LALOUETTE (Textes Sacrés et Textes Profanes de l'Ancienne Egypte. Des Pharaons et des Hommes, pp. 84-89), de John A. WILSON (ANET, pp. 199-201) e de S. LANGDON e Alan H. GARDINER ("The Treaty of Alliance between Hattusili, King of the Hittites, and the Pharaoh Ramesses II of Egypt", pp. 179-205). Para os parágrafos do texto hitita, foi apenas utilizada esta última versão de Langdon e Gardiner.

(32) Estação por vezes designada por estação do Inverno e que corresponde à época da saída das águas da cheia anual do Nilo.

(33) “Poderosa é a Verdade de Ré, Escolhido por Ré".

(34) "Casa de Ramessu-meriamon".

(35) Recordamos que a maior parte das negociações internacionais era conduzida por representantes autorizados para representar os seus soberanos, sendo que estes mensageiros, que serão os diplomatas actuais, assumiam um significado simbólico, reflectindo as relaçōes entre as potências. Christer Jönsson dá-nos um exemplo sintomático ao referir uma carta que Amen-hotep III envia ao rei da Babilónia, o qual, em vez de lhe enviar dignitários, 
enviou-the uma delegação de "zés-ninguéns" (EA 1). Cf. JÖNSSON, "Diplomatic Signaling in the Amarna Letterrs", em Amarna Diplomacy, pp. 202-203.

(36) Tratar-se-á de um dos casos em que é necessário ler com as devidas precauções o texto, na medida em que o rei do Hatti dificilmente se dirigiria ao faraó nestes termos.

(37) A cópia apresenta o significado de tradução/versão. O original egípcio desta secção é denunciado pelo uso da expressão "suplicar a paz" e pelo facto de os epítetos de Ramsés II serem notoriamente egípcios. Cfr. LANGDON e GARDINER, "The Treaty of Alliance between Hattusili, King of the Hittites, and the Pharaoh Ramesses II of Egypt", p. 186.

(38) No que respeita ao texto hitita, no mesmo consta: «[E assim seja. Ramessu-meri]amon, o grande rei, rei [do Egipto, o forte], [com Hattusili, o grande rei], rei da terra de Hatti, seu irmão, de forma a dar boa paz, [boa fraternidade e obter] um poderoso [rei]no (?) entre eles enquanto nós [vivermos] (e) [para sempre] [um tratado] fez. Ramessu-meriamon, o grande rei, rei do Egipto, o forte em todas as terras, filho [de] Menmaetré, o grande rei, rei do Egipto, o forte, filho do filho de Menpehtiré, o grande rei, [rei do Egip]to, o forte, até Hattusili, o grande rei, rei da terra de Hatti, o forte, filho de Mursili, o grande rei, rei da terra de Hatti, o forte, filho do filho de Suppiluliuma, o grande rei, rei da terra de Hatti, o forte, vê, agora eu dou [boa] fraternidade, boa paz entre nós para sempre, de forma a dar boa paz, boa fraternidade através de [um tratado (?)] do Egipto com o Hatti para sempre. Assim é,n, pp. 186-187. Como se pode verificar, as duas formas apresentam semelhanças em termos de conteúdo e de fraseologia.

(39) Em egípcio terá o significado de ordenança, acordo.

(40) Prenome de Seti I, pai de Ramsés II, com o significado de "É permanente a verdade de Rén.

(41) Prenome de Ramsés I, avô de Ramsés II, com o significado de "Firme é o poder de Ré».

(42) No que respeita ao texto hitita, no mesmo consta: "Vê, o plano do grande rei, rei do Egipto, [e o grande rei], rei do Hatti desde a eternidade - o deus não permitiu a existência de hostilidades entre eles, [através de um tratado] para sempre. Vê, Ramessu-meriamon, o grande rei, rei do Egipto, de forma a fazer o plano [que Shamash e] Teshub fizeram para o Egipto com a terra de Hatti por causa da sua política que é desde a eternidade, malvadamente (?) [não se tornará host]il para fazer hostilidade entre eles até à eternidade e para todo o [sempre].", p. 187.

(43) Referência a um tratado anterior. John A. Wilson coloca a possibilidade de tal ocorrer com Horemheb. Cf. WILSON, "Treaty between the hittites and Egypt", em ANET, p. 199.

(44) No que respeita ao texto hitita, no mesmo consta: «Ramessu-meriamon, o grande rei, rei do Egipto, estabeleceu um tratado, sob uma tabuinha de prata, com Hattusili, o grande rei, rei da terra de Hatti, seu irmão, desde este dia para dar boa paz e boa fraternidade entre nós para sempre; e ele é um irmão para mim e está em paz comigo, e eu sou um irmão para ele e estou em paz com ele para sempre. E nós fizemos fraternidade, paz e boa vontade maiores do que a fraternidade e a paz de tempos anteriores, estabelecidas entre [o Egipto] e o Hatti. Vê, Ramessu-meriamon, o grande rei, rei do Egipto, está em boa paz e em boa fraternidade com Hattusili, o grande rei, rei da terra de Hatti. Vê, os filhos de Ramessu-meriamon, o rei do Egipto, estão em paz (e) são ir[mãos com] os filhos de Hattusili, o grande rei, rei da terra de Hatti, para sempre; e eles estão de acordo com o nosso plano da [nossa] fraternidade (e) da nossa paz. E o Egipto com a terra de Hatti - estão em paz, são irmãos como nós para sempre.", p. 188.

(45) Não sendo uma frase tipicamente egípcia, será talvez uma marca de tradução de uma expressão comum babilónia. 
(46) As duas versões, egípcia e hitita são próximas, à excepção da referência à morte de Muwatalli e à sua sucessão por Hattusili no texto egípcio. A versão hitita alude a uma tabuinha de prata enviada por Ramsés II a Hattusili, à semelhança da enviada por Hattusili a Ramsés II. Conf. LANGDON e GARDINER, "The Treaty of Alliance between Hattusili, King of the Hittites, and the Pharaoh Ramesses II of Egypt", p. 189.

(47) No que respeita ao texto hitita, no mesmo consta: "E Ramessu-meriamon, o grande rei, rei do Egipto, não transporá a fronteira da terra de Hatti para nela se apoderar de algo [para sempre]; e Hattusili, o grande rei, rei da terra de Hatti, não transporá a fronteira do Egipto para nele se apoderar de algo [para sempre].», p. 189. Neste caso a correspondência é bastante clara.

(48) No que respeita ao texto hitita, no mesmo consta: "Vê, o decreto de eternidade que Shamash e Teshub fizeram para o Egipto e para a terra de Hatti [para fazer a paz] e fraternidade de modo a não promover hostilidade entre eles. E Vê, Ramessu-meria[mon, o grande rei], rei do Egipto, respeita-o para fazer a paz a partir deste dia. Vê, o Egipto e o Hatti [estão em paz, e] são irmãos para sempre.", p. 189. As diferenças entre as duas versões são consideráveis. Cf. LANGDON e GARDINER, "The Treaty of Alliance between Hattusili, King of the Hittites, and the Pharaoh Ramesses II of Egypt", p. 190.

(49) Proposta de tradução, ou também tradicional, com o significado de anterior.

(50) Muwatalli fora irmão de Hattusili, Mursili fora pai de Hattusili. Desta forma terá havido dois tratados anteriores, ou um tratado válido nos dois reinados.

(51) No que respeita ao texto hitita, no mesmo consta: «E se outro inimigo vier [contra] a terra de Hatti, e Hattusili, [o grande rei da terra de Hat]ti, me envia uma mensagem dizendo, 'Vem ter comigo para [me] ajudares contra ele'; então Ra[messu-meriam]on, o grande rei, rei do Egipto deverá enviar as suas tropas [e] os carros de combate e deverá massacrar [o seu inimigo e] deverá restaurar [con]fiança (?) na terra de Hatti.», p. 190.

(52) No que respeita ao texto hitita, no mesmo consta: " $E$ se Hattusili, o grande rei, rei da terra de Hatti, [estiver em cólera] contra súbditos seus [e eles] praticarem más acções contra ele, e enviar a Ramessu, o grande rei, rei do [Egipto] a este respeito; de imedi[ato] Ramessu-meriamon deverá enviar as suas tropas [e] os seus carros de combate, e eles deverão destruir todos [aqueles] contra quem [o seu coração ficar em cólera]", pp.190-191. Denota-se uma fraseologia diversa, mas um conteúdo próximo.

(53) No que respeita ao texto hitita, no mesmo consta: «[E se] outro inimigo vier contra o Egipto, e Ramessu-meriamon, o rei do Egipto, teu irmão, [enviar mensagem] a Hattusili, rei da terra de Hatti, seu irmão, dizendo, "[Ve]m ajudar-me contra ele"; de imediato deve $\mathrm{Ha}$ [ttusili], rei da terra de Hatti, enviar as suas tropas [e] os seus [carros de combate]; ele [deve massacrar] o meu inimigo.", p. 191.

(54) No que respeita ao texto hitita, no mesmo consta: "E se Ramessu, [o grande rei, rei] do Egipto, estiver em cólera contra súbditos seus, e eles cometerem más acções contra [si, e eu enviar] a Hattusili, rei da terra de Hatti, meu irmão, a [esse] respeito; então Hattusili, o grande rei, rei da terra de Hatti, deve enviar as suas tropas (e) os seus carros de combate e eles deverão destruir todos [eles]; e eu ...", p. 191.

(55) No que respeita ao texto hitita, no mesmo consta: «E vê o filho de Hattusili, rei da terra de Hatti, [o tratado que] nós (?) fizemos .... no lugar de Hattusili, seu pai, depois de anos, ... da terra de Hatti cometeram más acções .... carros de combate onde (?) devo eu regressar ... na terra de Hatti (?)», p. 192. O texto perde-se aqui.

(56) Não existe cláusula similar para a parte egípcia. Donald B. Redford comenta, neste ponto, que Ramsés II não permitiria estrangeiros intrometerem-se no que respeitasse ao "Trono de Hórus". Cf. REDFORD, Egypt, Canaan and Israel in Ancient Times, p. 190. 
(57) Como refere Donald B. Redford, atendendo a que Urhi-Tesub, filho de Muwatalli destituído do poder por Hattusili, havia fugido para a corte de Ramsés II e ainda se encontraria aí, estas cláusulas poderiam ter sido elaboradas tendo esta situação em mente. No entanto, aparentemente, Hattusili não terá pressionado Ramsés para reenviar o seu sobrinho para - Hatti; ver REDFORD, Egypt, Canaan and Israel in Ancient Times, p. 190. Mario Liverani realça igualmente o facto de este tratado estar claramente relacionado com a presença de Urhi-Tesub no Egipto, chegando mesmo a afirmar ser em parte causado por tal facto. Cf. LIVERANI, Prestige and Interest, International Relations in the Near East ca. 1600-1100 b.C. p. 110.

(58) Raymond Westbrook salienta que entre reis de igual estatuto, não haveria obrigação "legal" de reenviar os fugitivos sob pedido a menos que tal fosse especificado em tratado, como é aqui o caso, o que ocorria com alguma frequência. Cf. WESTBROOK, "International Law in the Amarna Age", em Amarna Diplomacy, p. 36.

(59) Salienta-se aqui a presença do selo de Puduhepa, reforçando o papel suficientemente importante da rainha nos assuntos de "Estado" para o seu selo constar do tratado.

\section{Bibliografia}

Cyril ALDRED, The Egyptians, Col. Ancient Peoples and Places, Londres: Thames and Hudson, 1984

Luís Manuel de ARAÚJO, "Kadech", em Dicionário do Antigo Egipto, Lisboa: Editorial Caminho, 2001, pp. 470-472

Luís Manuel de ARAÚJO, "A batalha de Kadech», em A Guerra na Antiguidade, António Ramos dos Santos e José Varandas (coord.), Lisboa: Caleidoscópio e Centro de História da Universidade de Lisboa, 2006, pp. 55-102.

John BAINES e Jaromir MÁLEK, Atlas of Ancient Egypt, Oxford: Phaidon Press, 1981

José Nunes CARREIRA (ed.), Historiografia Hitita, Lisboa: Edições Colibri, Centro de História da Faculdade de Letras da Universidade de Lisboa, 1999

Raymond COHEN e Raymond WESTBROOK (ed.), Amarna Diplomacy, The Beginnings of International Relations, Baltimore, Londres: The Johns Hopkins University Press, 2002

Geraldo Coelho DIAS, «Hatti» e «Hattusili», em Dicionário do Antigo Egipto, Lisboa: Editorial Caminho, 2001, p. 408

François DAUMAS, La Civilisation de l'Egypte Pharaonique, Paris: Arthaud 1965

A. ERMAN e H. RANKE, La Civilisation Égyptienne, Paris: Payot, 1982

Alan GARDINER, Egyptian Grammar, being an Introduction to the Study of Hieroglyphs, 3. ed. revista, Griffith Institute, Ashmolean Museum, Oxford: Oxford University Press, 1957

Alan GARDINER, Egypt of the Pharaohs. An Introduction, Oxford: Oxford University Press, 1981

Hans GOEDICKE (ed.), Perspectives on the Battle of Kadesh, Baltimore: Halgo, Inc, 1985

Nicolas GRIMAL, Histoire de l'Égypte Ancienne, Paris: Librairie Arthème Fayard, 1988

O. R. GURNEY, The Hitites, $2 .^{9}$ ed., Harmondsworth: Penguin Books, 1980

Erik HORNUNG, History of Ancient Egypt, Edimburgo: Edinburgh University Press, 1999

Claire LALOUETTE, L'Empire des Ramsès, Paris: Librairie Arthème Fayard, 1985 
Claire LALOUETTE, Textes Sacrés et Textes Profanes de l'Ancienne Egypte. Des Pharaons et des Hommes, Paris: Éd. Gallimard, 1984

S. LANGDON e Alan H. GARDINER, "The Treaty of Alliance between Hattusili, King of the Hitites, and the Pharaoh Ramesses II of Egypt", The Journal of Egyptian Archaeology, vol. 6, n. ${ }^{\circ}$ 3., Londres: Egypt Exploration Society, 1920, pp. 179-205

Miriam LICHTHEIM, Ancient Egyptian Literature, II: The New Kingdom, Berkeley, Los Angeles, Londres: University of Califórnia Press, 1976

Mario LIVERANI, Antico Oriente. Storia, Società, Economia, Roma, Bari: Editori Laterza, 1988

Mario LIVERANI, Prestige and Interest, International Relations in the Near East ca. 16001100 b.C, Padova: Sargon Sri, 1990

Donald B. REDFORD, Egypt, Canaan and Israel in Ancient Times, Princeton: Princeton University Press, 1992

José das Candeias SALES, A Ideologia Real Acádica e Egípcia. Representações do poder político pré-clássico, Lisboa: Editorial Estampa, 1997

António Augusto TAVARES, Impérios e Propaganda na Antiguidade, Lisboa: Editorial Presença, 1988

Dominique VALBELLE, Les Neuf Arcs. L'Égyptien et les étrangers de la Préhistoire à la conquête d'Alexandre, Paris: Armand Colin, 1990

John A. WILSON, "The Texts of the Battle of Kadesh". The American Journal of Semitic Languages and Literatures, vol. $43, n .^{\circ} 4$, Chicago: The University of Chicago Press, 1972, pp. 266-287

John A. WILSON, "Treaty between the hittites and Egypt", em James B. Pritchard (ed.), Ancient Near Eastern Texts relating to the Old Testament, 3. ed., Princeton: Princeton University Press, 1969

Jean YOYOTTE, "Armée", em Georges Posener (dir.), Dictionnaire de la Civilisation Égyptienne, Paris: Fernand Hazan, 1970, pp. 21-23 